\title{
Phase Equilibria and Diffusion of the Future
}

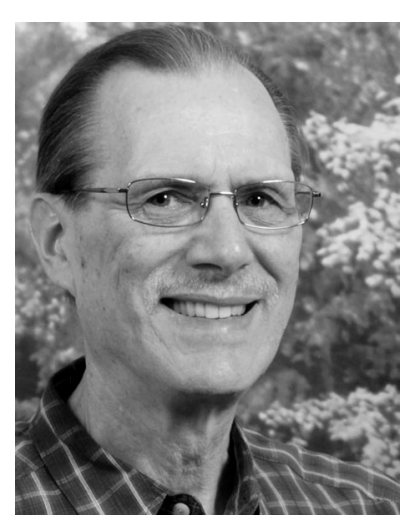

John E. Morral
Editorial for JPED April 2014

A few years ago a bestselling book was published entitled Physics of the Future, by Michio Kaku. Professor Kaku is a well known physicist, string theorist, and author of popular books on science. His goal was to predict "what life would be like during the next 100 years." Following the example of Jules Verne, he based his projections on discussions with leading scientists from around the world. Reviewers found the book "fascinating, erudite, and entertaining." It describes a digital world filled with sensors, robots, and extraordinary medical treatments. One reviewer, however, complained that the book was primarily about future technology and glossed over the topic of future physics. As one might expect, future developments in Phase Equilibria and Diffusion were glossed over as well.

Thinking it would be helpful to predict the future of our field as preparation for upcoming opportunities, I followed Kaku's example and asked experts in our field for their predictions about the future. Unlike Professor Kaku, I asked only for developments in the next 10 years, not the next 100 . That may be why no paradigm changing predictions were received. Future developments were projected to be incremental, not transformative.

For example, incremental increases were predicted in the number of people calculating, instead of measuring, thermodynamic properties and phase diagrams. Everyone agreed that fewer experiments may be needed in the future, but all agreed experiments would still be required to validate calculated properties, including kinetic properties like atomic mobilities of alloys. There was agreement, as well, that density functional theory (DFT) will continue to be the basis for first-principles calculations of properties for the next decade.

Comments received included the role of improved databases as a driver for expanding the ability of current software in all their various forms to aid in designing materials and processes. Once again, however, the predictions were for incremental and not transformative changes. Was this the result of looking only 10 years ahead? John Wanamaker, U.S. Postmaster General 18891897, predicted in 1893 that the U.S. mail would rely on stagecoach and horseback delivery for the next 100 years. If this prediction had been only for the next 10 years, his comments would be forgotten now and he would be known just as an extraordinary innovator who founded one of the first and largest department stores in the USA and introduced major reforms to the U.S. Postal Service.

In 1963 the Nobel laureate Dennis Gabor wrote in his book Inventing the Future that "the future cannot be predicted, but futures can be invented." This suggests why predictions about the future fail, for who can predict the giant transformative steps that can spring from an inventive mind? It was not done here. But in time you our readers will invent the future of Phase Equilibria and Diffusion in your minds and in your laboratories.

\author{
John E. Morral \\ Emeritus Professor, \\ The Ohio State University, \\ Columbus, $\mathrm{OH}$, USA \\ E-mail: jemorral@gmail.com
}

